\title{
Etiology and Viral Genotype in Patients with End-Stage Liver Diseases admitted to a Hepatology Unit in Colombia
}

\author{
Fabian Cortes-Mancera, ${ }^{1,2}$ Carmen Luisa Loureiro, ${ }^{3}$ Sergio Hoyos, ${ }^{1,4}$ \\ Juan-Carlos Restrepo, ${ }^{1,4}$ Gonzalo Correa, ${ }^{1,4}$ Sergio Jaramillo, , 4 \\ Helene Norder, ${ }^{5}$ Flor Helene Pujol, ${ }^{3}$ and Maria-Cristina Navas ${ }^{1}$ \\ ${ }^{1}$ Grupo de Gastrohepatología, Facultad de Medicina, Universidad de Antioquia, Medellín, Colombia \\ ${ }^{2}$ Instituto Tecnológico Metropolitano (ITM), Institución Universitaria Adscrita a la Alcaldía de Medellín, Medellín 549 59, Colombia \\ ${ }^{3}$ Laboratorio de Virología Molecular, CMBC, Instituto Venezolano de Investigaciones Científicas, Apdo. 20632, Caracas 1020A, \\ Venezuela, Caracas, Venezuela \\ ${ }^{4}$ Unidad de Hepatología y Trasplante Hepático, Hospital Pablo Tobón Uribe (HPTU), Calle 78B 69-240, Medellín, Colombia \\ ${ }^{5}$ Department of Virology, Swedish Institute for Infectious Disease Control, 17182 Solna, Sweden
}

Correspondence should be addressed to Maria-Cristina Navas, mcnavasn@gmail.com

Received 21 March 2011; Accepted 21 July 2011

Academic Editor: Isabelle Chemin

Copyright (C) 2011 Fabian Cortes-Mancera et al. This is an open access article distributed under the Creative Commons Attribution License, which permits unrestricted use, distribution, and reproduction in any medium, provided the original work is properly cited.

\begin{abstract}
Hepatitis B virus (HBV) and hepatitis $\mathrm{C}$ virus (HCV) infections are the principal risk factor associated to end-stage liver diseases in the world. A study was carried out on end-stage liver disease cases admitted to an important hepatology unit in Medellin, the second largest city in Colombia. From 131 patients recruited in this prospective study, $71 \%$ of cases were diagnosed as cirrhosis, $12.2 \%$ as HCC, and $16.8 \%$ as cirrhosis and HCC. Regarding the risk factors of these patients, alcohol consumption was the most frequent $(37.4 \%)$, followed by viral etiology $(17.6 \%)$. Blood and/or hepatic tissue samples from patients with serological markers for HCV or HBV infection were characterized; on the basis of the phylogenetic analysis of HCV 5' UTR and HBV S gene, isolates belonged to HCV/1 and HBV/F3, respectively. These results confirm the presence of strains associated with poor clinical outcome, in patients with liver disease in Colombia; additionally, HBV basal core promoter double mutant was identified in HCC cases. Here we show the first study of cirrhosis and/or HCC in Colombian and HBV and HCV molecular characterization of these patients. Viral aetiology was not the main risk factor in this cohort but alcohol consumption.
\end{abstract}

\section{Introduction}

Hepatitis B virus (HBV) and hepatitis C virus (HCV) infections are a serious health concern due to their global distribution and direct relationship with liver cirrhosis and hepatocellular carcinoma (HCC) development. In average, 57 and $78 \%$ of cirrhosis and HCC cases are attributable to these hepatotropic viruses $[1,2]$. HCC is the most common primary liver tumor that presents a heterogeneous prevalence among different ethnic groups and geographic regions. More than $80 \%$ of HCC cases occur in Asia and Africa: Japan, China, and Niger, holding an incidence of 20-500 cases/100.000 inhabitants; South American countries present a lower incidence (5 cases/100.000 inhabitants), particularly in Colombia; an incidence of 2 cases/100.000 inhabitants is estimated [3].

Although clinical significance of the HBV and HCV genotypes has not been completely elucidated, increasing epidemiological data suggests that some genotypes could be related to higher risk of HCC development [4-8]. For example, the HCV subtype $1 \mathrm{~b}(\mathrm{HCV} / 1 \mathrm{~b})$ is associated with more severe clinical outcome and poor antiviral response. Moreover patients infected with HBV genotype C (HBV/C) present a higher frequency of HCC than HBV/B-infected patients [9-13]; patients with HBV/F seem to follow a similar tendency like HBV/C-infected patients $[14,15]$. In the same way, a double mutation (A1762T/G1764A) in HBV 
basal core promoter $(\mathrm{BCP})$ region has been implicated with severe clinical outcome and poor response to nucleosides' analogues [4, 16-20].

Considering that Latin American region is extremely diverse in culture, ethnicity, socioeconomic status, and health systems, the research findings of neighbour countries are not totally comparable. Until now, the epidemiological pattern of end-stage liver diseases in Colombia is unknown, and no report has described the molecular characterization of HBV and HCV in this group of patients [21, 22]. In the present study, aetiology and viral genotypes, subgenotypes/subtypes, and HBV pre-C/C mutants were analyzed in cirrhosis and/or HCC cases attended at the Pablo Tobon Uribe Hospital (HPTU) during the period 2005-2007 in Medellin, the second largest city in Colombia.

\section{Materials and Methods}

2.1. Patients. From February 2005 to February 2007, 131 patients with end-stage liver diseases (cirrhosis and/or HCC) were enrolled in this study; previous voluntary informed consent sign was obtained. All patients were recruited at the Hepatology Unit of HPTU in Medellin city, Colombia. Diagnosis of liver cirrhosis was established according to the following findings: hepatic encephalopathy, ascites, digestive bleeding due to esophageal varices, coagulopathy, spontaneous bacterial peritonitis, hepatorenal syndrome, imaging criteria (ultrasonography, magnetic resonance, and tomography), and/or liver biopsy; HCC diagnosis was performed following the guidelines of the European Association for the Study of the Liver (EASL).

2.2. Samples. Serum and liver tissue samples were obtained from patients who underwent liver transplantation. Both types of material were kept at $-70^{\circ} \mathrm{C}$ until processing; the following serological markers were assessed in samples: $\mathrm{HBsAg}$, total anti-HBc, and anti-HCV (Roche).

2.3. Viral Genome Detection. Total RNA and DNA were isolated from samples with serological markers for $\mathrm{HBV}$ and/or HCV, using Trizol reagent (Invitrogen, USA). HBV DNA was amplified by PCR, using S-gene-specific primers [23]. The HCV genome was assessed by nested RT-PCR, using flanking primers for $5^{\prime} \mathrm{UTR}$, following a protocol previously published [24, 25]. As a positive control, samples with HBV or HCV genome detection were used; liver tissue from a patient with diagnosis of cirrhosis associated to alcohol intake abuse, without HBV or HCV infection, was used as negative controls. All assays were performed in duplicate.

2.4. Molecular Characterization of $H B V$ and $H C V$. In order to know the viral genotype, different PCR products were sequenced to perform a phylogenetic analysis; HCV genotyping was conducted with the $5^{\prime}$ conserved region (5'UTR), using the primers' set described before for HCV detection $[24,25]$. To amplify the full HBV genome (3200 nts), a first round of PCR was performed with P1 and P2 primers [26].
A second round of PCR was carried out with some isolates using primers 58p-1450n, 1860p-2853n, 2440p-58n, 1101p$\mathrm{P} 2, \mathrm{P} 1-2440 \mathrm{n}$, and $1450 \mathrm{p}-\mathrm{P} 2$, to obtain the total genome sequences by subregions' amplification [27]. When total $\mathrm{HBV}$ genome was not amplified with the primers mentioned above, the small S gene fragment was amplified using 58P$1101 \mathrm{~N}$ in the first round and s3-s3as (319 nt) in a second round $[27,28]$, or hep3-hep33 as a unique round of PCR [29].

All sequences obtained were compared with GenBankavailable sequences of known genotypes, including subgenotypes/subtypes. Phylogenetic analyses by neighbour joining, maximum parsimony, and maximum likelihood were conducted with PAUP 4.0, MEGA 4.1; Treeview program was used for tree representation. Recombination events were studied by bootscanning and similarity analysis (Simplot).

To evaluate mutations in HBV BCP (A1762T/G1764A) and pre-C/C (G1896A), analysis of the sequences was carried out by comparison with other GenBank sequences of different HBV genotypes considering mutants and wild type. BioEdit program was used for this purpose. The accession numbers of sequences included are as follows: HBV: FJ589065; FJ589066; FJ589067; FJ589068; FJ589069; FJ589070; HCV: JF693486, JF693487, JF693488, JF693489.

\section{Results}

3.1. Demographic and Clinical Characteristics of Patients. The mean age of the 131 individuals was 58.1 years (range: 1785 years); most of patients recruited were males $(65.6 \%)$. According to the followed clinical guidelines, $71 \%$ evidenced cirrhosis, 12.2\% HCC, and 16.8\% cirrhosis and HCC $\left(\mathrm{HCC} / \mathrm{Ci}^{*}\right)$. Interestingly, when risk factors were analyzed alcohol intake abuse was the most frequent risk factor (37.4\%), followed by viral etiology $(17.6 \%)$, autoimmunity (9.9), NASH $(7.6 \%)$, and other causes such as metabolic disorders and biliary disease (16.8\%); $10.7 \%$ of the cases were not associated to any risk factor assessed (Table 1). The most frequent clinical manifestations were esophageal varices $(64 \%)$, ascites $(61.8 \%)$, coagulopathy $(46 \%)$, and hepatic encephalopathy $(38.2 \%)$; most of patients were scored at the Child B and C (>75\%), indicating an advanced chronic liver disease in patients enrolled.

From 131 patients included in the present study, 14 were positive for the HBsAg serological marker (10.7\%) and 9 for anti-HCV (6.9\%); most of patients infected by HBV and $\mathrm{HCV}$ were males $(60.8 \%)$. The mean age of these 23 patients was 56.6 (range 34-74 years). Among them, 22 had diagnosis of liver cirrhosis and 7 had HCC in addition $\left(\mathrm{HCC} / \mathrm{Ci}^{*}\right)$; just one patient had diagnosis of HCC without cirrhosis. According to the phenotype, 20 patients corresponded to non-Amerindian individuals; besides, the three others were patients from El Salvador, Venezuela, and Israel (Table 2).

3.2. Phylogenetic Analysis. In 4 out of 8 tissue samples from patients infected by $\mathrm{HCV}$, it was possible to successfully sequence the $5^{\prime} \mathrm{UTR}$. The expected grouping was observed among Genbank sequences after phylogenetic analysis 


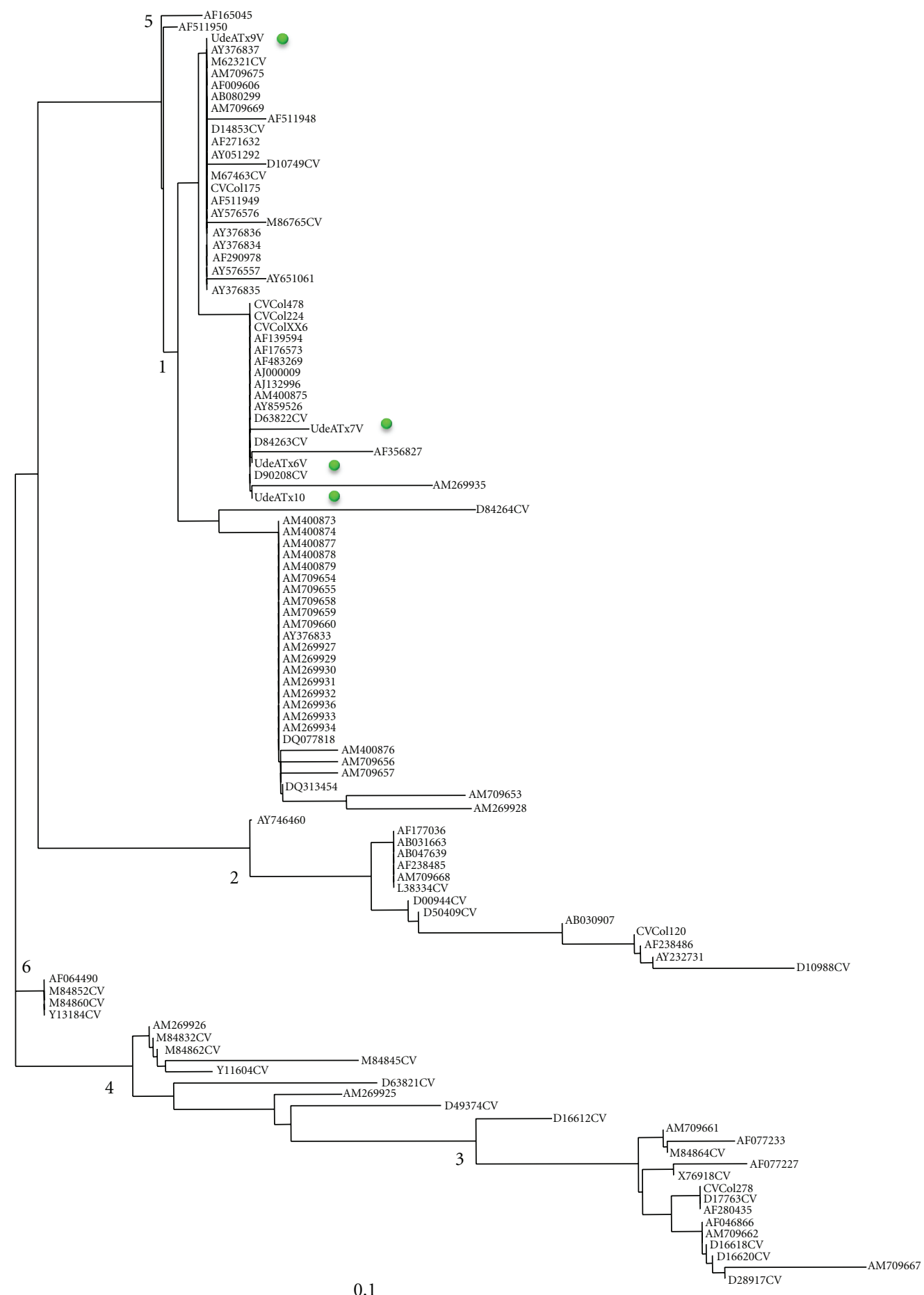

FIGURE 1: Unrooted Tree generated with MEGA software, using 5'UTR HCV sequences. Solid green circle indicates the position of isolate characterized in the present study. The accession number of the sequences are shown.

conduction, with minor method-dependent changes (data not shown). All four isolates belonged to HCV genotype 1 . Three HCV strains corresponded to HCV subtype $1 \mathrm{~b}$ and one to subtype 1a (Figure 1).

In the case of $\mathrm{HBV}$, seven strains were sequenced; four strains from liver tissues and three were serum sample derived. In one additional isolate (UdeA-072) the HBV genome was detected by PCR, although it was not possible to obtain a clear electropherogram after several assays. HBV $S$ gene sequence analysis showed that all isolates belonged to genotype $\mathrm{HBV} / \mathrm{F}$, validated by the HBV GenBank sequence grouping results and high bootstrap values observed in most tree branches. Similar topology was observed among trees generated by the different inference methods (data 
TABle 1: Description of End-stage liver disease cases recruited.

\begin{tabular}{lc}
\hline Characteristics & Proportion (\%) \\
\hline Risk factors & 37,4 \\
Alcohol intake & 17,6 \\
Viral etiology & 10,7 \\
Cryptogenic & 9,9 \\
Autoimmunity & 7,6 \\
NASH & 16,8 \\
Others* & \\
Clinical findings & 64 \\
\hline Esophageal varices & 61,8 \\
Ascites & 46 \\
Coagulopathy & 38,2 \\
Hepatic encephalopathy & 15,7 \\
Spontaneous bacterial peritonitis & 8,9 \\
Hepatorenal syndrome & \\
\hline
\end{tabular}

${ }^{*}$ Metabolic disorders, biliary disease, or both.

not shown). Five isolates grouped into the clade of South American strains (Codes UdeA-009, UdeA-054, UdeA-056, UdeA-083, and UdeA-089); this clade included the first Colombian isolate characterized by Norder et al. [29]. Interestingly, one of the sequences analyzed (Code UdeA024) was less related to this clade (Figure 2).

The complete HBV genome was sequenced in four strains, two Colombian isolates (Codes UdeA-083 and UdeA089) one from Venezuela (Code UdeA-054), corresponding to subgenotype F3 (HBV/F3), and the sequence from El Salvador (Code UdeA-024), grouped in a different clade from the HBV/F3 (Figure 3). Indeed, UdeA-024, belonging to subgenotype F1a (HBV/F1a), was more closely related to strains from Central America countries (El Salvador, Costa Rica, and Nicaragua), in agreement with the origin of the patient. In the same phylogenetic analysis, partial sequences (S gen) of strains UdeA-009 and UdeA-056 were added. On the basis of strict consensus tree generated by maximum parsimony, these isolates corresponded to $\mathrm{HBV} / \mathrm{F} 3$; this grouping was supported by a bootstrap value higher than 80 .

The results obtained in the present phylogenetic analysis are in agreement with the HBV and HCV genotype geographic distribution in Latin America. Additionally, this report corresponds to the first description of $\mathrm{HBV} / \mathrm{F}$ in Colombian patients with severe liver disease.

3.3. Characterization of G1896A and A1762T/G1764A Mutants. To establish the presence of G1896A and A1762T/G1764A mutants, pre-C/C sequences were aligned with HBV wild-type and mutant prototypes available in GenBank. The BCP analysis showed that isolates UdeA-083 and UdeA-089 carried the double mutation A1762T/G1764A. These isolates were recovered from the Colombian patients with diagnosis of $\mathrm{HCC} / \mathrm{Ci}^{*}$ (Table 3 ). In addition, $\mathrm{T}$ at 1858 nucleotide $\left(\mathrm{T}^{1858}\right)$ was detected in isolates UdeA-024 and UdeA-054 and $\mathrm{C}^{1858}$ in samples UdeA-083 and UdeA-089. In UdeA-054, mutant G1896A was

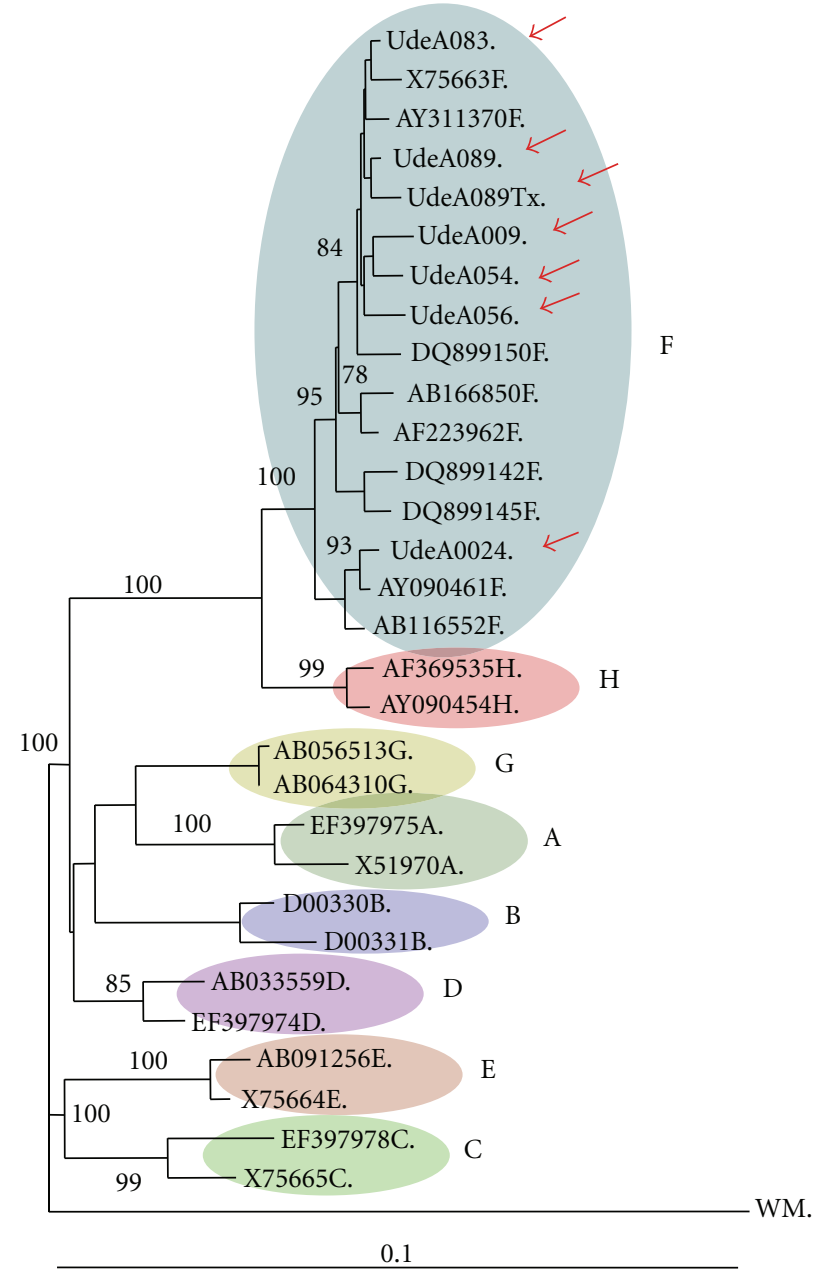

Figure 2: Phylogenetic tree of HBV genotype A to $\mathrm{H}$ generated by the Neighbour Joining method (PAUP), using HBV $S$ gene sequences The Hepatitis Woolly monkey virus (WM) sequence was used as outgroup. Red arrow: isolate characterized from cirrhosis and/or HCC cases. The accession number followed by genotype identity is indicated. Bootstrap values are shown (1000 repetitions). HKY was used to assess distances.

also identified in addition to $\mathrm{T}^{1858}$. The G1896A mutation correlated with detection of no HBeAg by ELISA in the corresponding serum sample (Table 3 ).

\section{Discussion}

This paper corresponds to the first study of aetiology description in Colombian patients with end-stage liver diseases and the molecular characterization of HBV and HCV strains detected in this group of patients.

One of forty deaths around the world is due to endstage liver disease. In the present study, $71 \%$ of the patients correspond to cirrhosis cases and $29 \%$ to HCC, a similar result to other descriptions reported in countries of the region [1, 30, 31]. Among these 131 patients, alcohol intake abuse was the most frequent risk factor observed $(37.4 \%)$, followed by viral infections (17.6\%). Although 
TABLE 2: Clinical and demographic characteristics of patients with positive serological markers for HBV and HCV.

\begin{tabular}{|c|c|c|c|c|c|c|c|c|c|}
\hline \multirow{2}{*}{ Code } & \multirow{2}{*}{ Diagnosis } & \multirow{2}{*}{ Origin } & \multirow{2}{*}{ Age } & \multirow{2}{*}{ Gender } & \multirow{2}{*}{ Alcohol* $^{*}$} & \multicolumn{2}{|c|}{ Type of simple } & \multicolumn{2}{|c|}{ Serological marker } \\
\hline & & & & & & Serum & $\begin{array}{c}\text { Liver } \\
\text { tissue }\end{array}$ & HBsAg & Anti-HCV \\
\hline UdeA-001 & $\mathrm{Ci}$ & Colombia & 68 & $\mathrm{~F}$ & 4 & NA & $\underline{\text { Yes }}$ & Neg & Pos \\
\hline UdeA-002 & $\mathrm{Ci}$ & Colombia & 59 & M & 4 & NA & $\underline{\text { Yes }}$ & Neg & Pos \\
\hline UdeA-003 & $\mathrm{Ci}$ & Colombia & 68 & M & 4 & NA & Yes & Neg & Pos \\
\hline UdeA-004 & $\mathrm{Ci}$ & Colombia & 47 & M & 4 & Yes & NA & Pos & Neg \\
\hline UdeA-006 & $\mathrm{HCC}+\mathrm{Ci}$ & Colombia & 48 & M & 4 & NA & Yes & Neg & Pos \\
\hline UdeA-009 & $\mathrm{Ci}$ & Colombia & 69 & M & 1 & Yes & NA & Pos & Neg \\
\hline UdeA-015 & $\mathrm{HCC}+\mathrm{Ci}$ & Colombia & 68 & $\mathrm{~F}$ & 9 & $\overline{\mathrm{NA}}$ & Yes & Neg & Pos \\
\hline UdeA-024 & $\mathrm{Ci}$ & El Salvador & 60 & M & 9 & NA & Yes & Pos & Neg \\
\hline UdeA-054 & $\mathrm{Ci}$ & Venezuela & 47 & M & 3 & Yes & Yes & Pos & Neg \\
\hline UdeA-056 & $\mathrm{HCC}+\mathrm{Ci}$ & Colombia & 56 & $\mathrm{~F}$ & 4 & Yes & $\overline{\mathrm{NA}}$ & Pos & Neg \\
\hline UdeA-058 & $\mathrm{HCC}+\mathrm{Ci}$ & Colombia & 53 & M & 9 & $\overline{\text { Yes }}$ & NA & Pos & Neg \\
\hline UdeA-061 & $\mathrm{Ci}$ & Colombia & 47 & $\mathrm{~F}$ & 4 & Yes & NA & Pos & Neg \\
\hline UdeA-065 & $\mathrm{Ci}$ & Colombia & 58 & F & 1 & NA & $\underline{\text { Yes }}$ & Neg & Pos \\
\hline UdeA-069 & HCC & Colombia & 64 & F & 4 & NA & Yes & Neg & Pos \\
\hline UdeA-070 & $\mathrm{Ci}$ & Colombia & 34 & M & 4 & NA & Yes & Neg & Pos \\
\hline UdeA-072 & $\mathrm{Ci}$ & Israel & 49 & M & 3 & Yes & $\underline{\text { Yes }}$ & Pos & Neg \\
\hline UdeA-077 & $\mathrm{Ci}$ & Colombia & 57 & M & 1 & Yes & NA & Pos & Neg \\
\hline UdeA-083 & $\mathrm{HCC}+\mathrm{Ci}$ & Colombia & 67 & F & 4 & Yes & $\underline{\text { Yes }}$ & Pos & Neg \\
\hline UdeA-087 & $\mathrm{Ci}$ & Colombia & 48 & M & 2 & Yes & NA & Pos & Neg \\
\hline UdeA-089 & $\mathrm{HCC}+\mathrm{Ci}$ & Colombia & 47 & $\mathrm{~F}$ & 4 & $\underline{\text { Yes }}$ & Yes & Pos & Neg \\
\hline UdeA-099 & $\mathrm{Ci}$ & Colombia & 56 & M & 4 & $\overline{\text { Yes }}$ & $\overline{\mathrm{NA}}$ & Pos & Neg \\
\hline UdeA-101 & $\mathrm{Ci}$ & Colombia & 74 & $\mathrm{~F}$ & 4 & Yes & NA & Pos & Neg \\
\hline UdeA-124 & $\mathrm{HCC}+\mathrm{Ci}$ & Colombia & 57 & M & 2 & Yes & NA & Pos & Neg \\
\hline
\end{tabular}

ci: Cirrhosis, HCC: hepatocellular carcinoma, M: male, F: female, ${ }^{*}$ Alcohol intake: for male/(female) 1: >80 g/day (40g/day); 2: 50-80 g/day (20-40 g/day); 3: $<50$ g/day (20 g/day) 4: no intake; 9: no data; Yes: available; NA: nonavailable; Yes: HBV/HCV-positive sample by molecular analysis; Pos: positive serological result;Neg: negative serological result.

TABLE 3: Molecular characterization of HBV isolates corresponding to End-stage liver disease cases: Genotype, Subgenotype and precore/core mutants.

\begin{tabular}{|c|c|c|c|c|c|c|c|c|c|c|}
\hline \multirow{3}{*}{ Code } & \multirow{3}{*}{ Diagnosis } & \multirow{3}{*}{ Genotype } & \multirow{3}{*}{ Subgenotype } & \multicolumn{4}{|c|}{ Mutation } & \multicolumn{3}{|c|}{ HBV serological markers } \\
\hline & & & & \multicolumn{2}{|c|}{ pre-C } & \multicolumn{2}{|c|}{$\mathrm{BCP}$} & \multirow[t]{2}{*}{ HBsAg } & \multirow{2}{*}{$\begin{array}{c}\operatorname{IgG} \\
\text { anti-HBc }\end{array}$} & \multirow[t]{2}{*}{ HBeAg } \\
\hline & & & & 1858 & 1896 & 1762 & 1764 & & & \\
\hline UdeA-009 & $\mathrm{Ci}$ & $\mathrm{F}$ & $\mathrm{F} 3^{\mu}$ & - & - & 一 & - & Pos & Pos & Neg \\
\hline UdeA-024 & $\mathrm{Ci}$ & $\mathrm{F}$ & $\mathrm{F} 1 \mathrm{a}^{\infty}$ & $\mathrm{T}$ & G & A & G & Pos & Pos & Neg \\
\hline UdeA-054 & $\mathrm{Ci}$ & $\mathrm{F}$ & $\mathrm{F} 3^{\infty}$ & $\mathrm{T}$ & $\mathrm{A}^{\alpha}$ & A & G & Pos & Pos & Neg \\
\hline UdeA-056 & $\mathrm{HCC} / \mathrm{Ci}^{*}$ & $\mathrm{~F}$ & $\mathrm{~F} 3^{\mu}$ & - & - & 一 & - & Pos & Pos & Neg \\
\hline UdeA-083 & $\mathrm{HCC} / \mathrm{Ci}^{*}$ & $\mathrm{~F}$ & $\mathrm{~F} 3^{\infty}$ & $\mathrm{C}$ & G & $\mathrm{T}^{*}$ & $A^{*}$ & Pos & Pos & $\mathrm{Neg}$ \\
\hline UdeA- $089^{\beta}$ & $\mathrm{HCC} / \mathrm{Ci}^{*}$ & $\mathrm{~F}$ & $\mathrm{~F} 3^{\infty}$ & $\mathrm{C}$ & G & $\mathrm{T}^{*}$ & $\mathrm{~A}^{*}$ & Pos & Pos & $\mathrm{Neg}$ \\
\hline
\end{tabular}

$\beta$ : both, tissue and serum samples, Ci: cirrhosis, $\mathrm{HCC} / \mathrm{Ci}^{*}$ : cirrhosis and hepatocellular carcinoma, $\infty$ : based on complete genome analysis, $\mu$ : based on $\mathrm{S}$ gene sequence analysis, - : no data, $\alpha$ : nonsense mutation, ${ }^{*}$ : double mutant, Pos: positive, Neg: negative. Strains isolated from Colombian patients: UdeA-009, UdeA-024, UdeA-056, UdeA-083, and UdeA-089. Strain isolated from a Venezuelan patient: UdeA-54. 1.

this epidemiological pattern is usually found in developed countries, the high proportion of males (in general males have a higher alcohol intake than females) in the present study and the HBV vaccination status in Colombia could be contributing to the risk factors' pattern of the population study [32]. On the other hand, the prevalence of cryptogenic cirrhosis and autoimmune liver disease is according to previous reports $[1,30]$.

As previously mentioned, the frequency of cirrhosis and HCC cases associated to viral etiology in the present study 


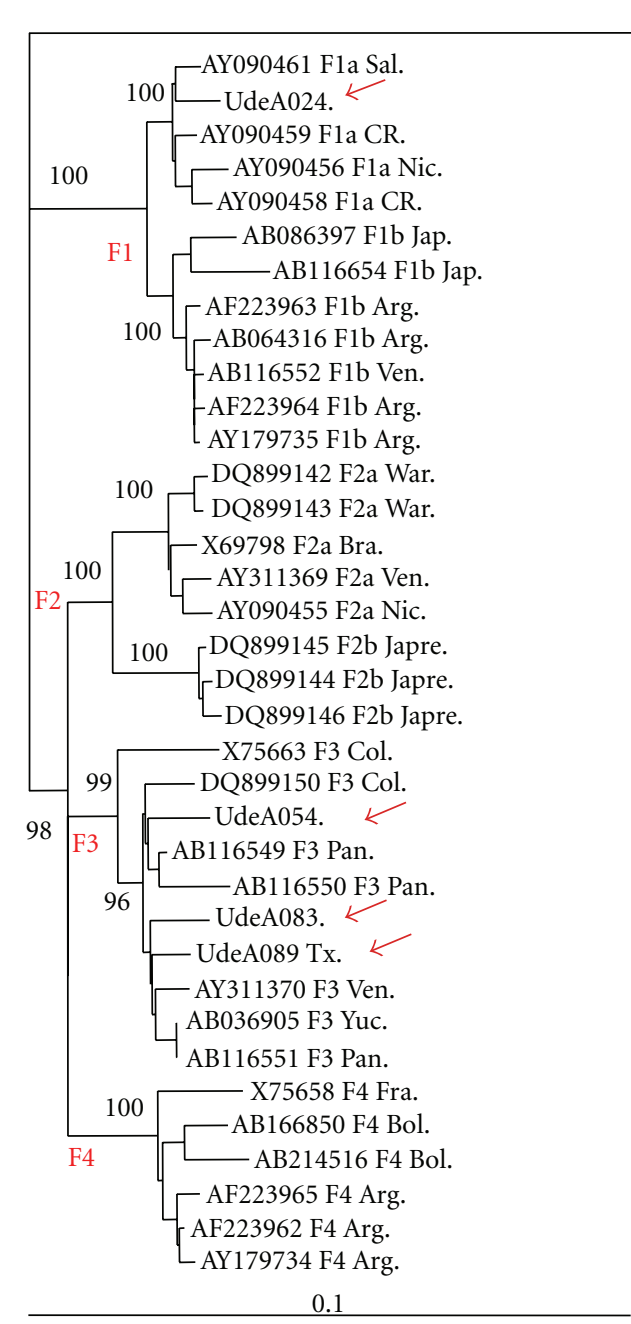

Figure 3: HBV subgenotyping (F1-F4), based on the complete genome analysis using PAUP program. Sequence of genotype G was used as outgroup (AB056513). The accession number and subgenotype are indicated followed by the isolate origin letters code (Sal: El Salvador, CR: Costa Rica, Nic: Nicaragua, Jap: Japan, Arg: Argentina, Ven: Venezuela, Col: Colombia, Pan: Panama, Bol: Bolivia, and two Amerindian tribes from Venezuela War: Warao tribe, Japre: Japreira tribe). Red arrow: sequences belonging to the present study. Bootstrap values are shown (1000 replications).

was low $(17.6 \% ; 23 / 131)$. Only $10.7 \%(14 / 131)$ and $6.9 \%$ (9/131) of these patients were positive for serological markers of HBV (HBsAg) or HCV (anti-HCV) infection, respectively.

The HCV-related HCC has increased in several countries; $80 \%$ of infected patients with $\mathrm{HCV}$ progress to chronic infection, while $20 \%$ of them develop cirrhosis, and at least $5 \%$ of these evolve to HCC [33]. In Latin America, the world health organization (WHO) estimates an intermediate prevalence of $\mathrm{HCV}$ infection (1-2.5\%); moreover, a low prevalence $(0.5-1 \%)$ has been reported among Colombian blood donor population [34-36].

As previously mentioned, Medellin is the second largest city in the country and the capital of Antioquia State (Department of Antioquia). Health authorities in Antioquia have reported a similar HCV prevalence since 2004 (0.20.3/100.000 inhabitants) (Indicadores Básicos 2004-2007).

Contrary to general population, studies in some Latin American countries show a high HCV prevalence in severe liver disease. Indeed, HCV infection is the predominant HCC risk factor in Argentina, Chile, and southeastern states of Brazil. Furthermore, in a recently prospective multicenter study of HCC cases from 9 Latin American countries, the main HCC risk factor was HCV infection (30.8\%), followed by alcohol (20.4\%), HBV infection (10.8\%), and then HCV plus alcohol (5.8\%) [37-39]. A similar tendency was observed in Mexican cirrhotic patients, where $39.5 \%$ of recruited patients presented alcohol intake abuse, followed by HCV infection (36.6\%) [40].

Considering the analysis of HCV sequences included in the phylogenetic analysis, the prototypes clustered according to the genotypes described in the literature (HCV/1-6), obtaining similar results with all methods conducted. Inside the main cluster of genotype $\mathrm{HCV} / 1$ was clearly observed clades assigned to subtype $\mathrm{HCV} / 1 \mathrm{a}$ and $\mathrm{HCV} / 1 \mathrm{~b}$; Colombian strains were grouping into these subtypes. Indeed, one isolate belongs to $\mathrm{HCV} / \mathrm{la}$ and three strains to $\mathrm{HCV} / 1 \mathrm{~b}$. This result is consistent with previous reports of $\mathrm{HCV}$ geographic distribution in Latin American countries where different genotypes are present $(\mathrm{HCV} / 1, \mathrm{HCV} / 2, \mathrm{HCV} / 3$, and $\mathrm{HCV} / 4$ ); however, genotype $\mathrm{HCV} / 1$ is the prevalent in most countries of the region including Colombia [41]. Indeed, $\mathrm{HCV} / 1$ has been described in some studies performed by different approaches in Colombian multitransfused patients, individuals with elevated aminotransferases, general population, and kidney transplant patients [42-45]. This is the first report based on sequence analysis and developed in samples of patients with severe liver disease in Colombia. Secondly, most of research findings agree that $\mathrm{HCV} / 1 \mathrm{~b}$ is related with higher risk of severe liver disease [23, 46-48]. It is important for health authorities in Colombia and other Latin American countries to develop studies that contribute to knowing the impact of genotype $\mathrm{HCV} / 1 \mathrm{~b}$ over the hepatitis $\mathrm{C}$ natural history in the region.

According to WHO, Colombia has a moderate endemicity for hepatitis B, although there are several epidemiological patterns given the geographic, ethnic, cultural, and socioeconomic status of the population. Actually, Sierra Nevada de Santa Marta, Orinoquian and Amazon basins, and southeastern part of the country corresponded to highprevalence regions for hepatitis B infection in this country. However Antioquia state holds a different behavior [49]; in fact, the general incidence of $\mathrm{HBV}$ infection in this state in the last years range was 2.7-4.4 per 100.000 inhabitants, while the prevalence in blood donors was $0.3 \%[49,50]$. As mentioned above, HBV infection was observed in $10.7 \%$ of the patients analyzed. The study population was recruited in Medellin, the second largest city in Colombia, in one of the most important units of hepatology in the country; even if it is possible that this hospital receives patients from rural area of Antioquia state and other Colombian states, most of the cases corresponded to people living in urban area and not from high-prevalence regions of hepatitis $B$ infection. 
This heterogeneity of hepatitis B situation is also described in Brazil; indeed, higher frequency of HBV infection than other risk factors has been described in HCC patients from states of northeastern and northern regions of Brazil but not in patients from southeastern states $[51,52]$.

The low HBV prevalence described in the present study contrasts with some studies conducted in Peru and Brazil, where HBV was reported in $42-63 \%$ of end-stage liver disease cases [51-56]. Contrary to these reports, a low HBV prevalence has been described among HCC patients from Chile $(6.8 \%)$ and Puerto Rico $(4 \%)$ [57, 58], similar to other works carried out in the United States, Japan, and western Europe [1]. On the other hand, on Ecuador a study conducted in 770 cirrhotic patients linked viral etiology to $2.8 \%$ of the cases, while alcohol intake was the most frequent risk factor associated (48.3\%) [59]. Whereas differences among studied populations (gender, age, origin), diagnosis, and viral markers are described above, additional studies will be necessary for clarifying the real statement of hepatotropic viruses in cases of cirrhosis and $\mathrm{HCC} / \mathrm{Ci}^{*}$ in Colombia and the region.

On the other hand, the phylogenetic analysis of HBV showed that HBV/F and subgenotype HBV/F3 were presented in serum and tissue samples of the Colombian population analyzed; subgenotypes HBV/F1a and HBV/F3 were also detected in two cases from El Salvador and Venezuela, respectively. These results are consistent with previously published reports about molecular diversity of these hepatotropic viruses, geographic distribution in Latin America, and their prevalence in severe forms of hepatic disease. In addition, the A1762T/G1764A double mutant, associated according to some authors with a poor clinical outcome, was described in strains isolated from Colombian patients with diagnosis of $\mathrm{HCC} / \mathrm{Ci}^{*}$. As mentioned before all isolates of HBV sequenced belonged to HBV/F. It has been proposed that HBV/F is autochthonous to America due to its predominance in different ethnic groups, in particular Amerindian [60]. In Colombia, few studies about HBV molecular characterization have been published. Two of them included samples from blood donor populations, showing a predominance of genotype HBV/F (77-87.23\%) $[21,22]$. This result is in agreement with our study and previous findings of genetic population founder carried out in the state of Antioquia [61, 62], which revealed that $90 \%$ of the genetic pool (mitochondrial DNA) corresponded to Amerindian origin. More recently, in Colombia was detected the genotype HBV/E in nine pregnant women, being the first description of an exclusively African HBV genotype circulating in South America [63]; this result also coincides with high frequency of African haplotypes in population from Choco state, at the pacific coast of Colombia [64]. The subgenotypes HBV/F1-F4 have a specific geographic distribution in America. Indeed, subgenotype HBV/F1a is predominant in Alaska, Nicaragua, Costa Rica, and El Salvador, while subgenotype HBV/F1b in Peru and Argentina. Subgenotype HBV/F2 is prevalent in Venezuela and Brazil and subgenotype HBV/F3 in Panama, Venezuela, and Colombia. Finally, subgenotype HBV/F4 is present in Bolivia and Argentina $[20,65]$. Devesa et al. and Alvarado et al. have characterized the HBV subgenotypes in samples from Colombian blood donor isolates; most of the isolates corresponded to HBV/F3. Genotype HBV/F was also recently characterized in samples from blood donor population from Medellin by our group (unpublished data). In the present study, the complete genome analysis in 4 out of $6 \mathrm{HBV}$ isolates from patients with cirrhosis or $\mathrm{HCC} / \mathrm{Ci}^{*}$ made it possible to classify 3 of them into subgenotype HBV/F3, and one strain into subgenotype $\mathrm{HBV} / \mathrm{F} 1 \mathrm{a}$, while partial analysis (small $\mathrm{S}$ gene sequence) of two others showed grouping with HBV/F3 prototypes.

The BCP and pre-C/C mutations have been associated with clinical outcome severity. One frequent mutation corresponds to $\mathrm{G} 1896 \mathrm{~A}$ in the pre- $\mathrm{C} / \mathrm{C}$ region which leads to a premature stop codon preventing $\mathrm{HBeAg}$ synthesis $[4,8,20$, 66]. When this region was analyzed, the G1896A mutation was characterized only in one isolate (UdeA-054), presenting in addition $\mathrm{T}^{1858}$, while the isolates UdeA-083 and UdeA-089 carry $\mathrm{C}^{1858}$. According to several studies, G1896A is frequent in genotype $\mathrm{HBV} / \mathrm{F}$ isolates that carry $\mathrm{T}^{1858}$. A hypothesis for this coevolution pattern is that hydrogen binding between nucleotides $1858-1896$ is necessary to maintain the low stem secondary structure of $\varepsilon$ signal [67]. The presence of G1896A in isolate UdeA-054 correlated with no detection of $\mathrm{HBeAg}$ by ELISA in serum sample (Table 3 ).

When BCP was analyzed, it was demonstrated that isolates UdeA-083 and UdeA-089 carried the double mutation A1762T/G1764A; these isolates corresponded to two Colombian patients with diagnosis of $\mathrm{HCC} / \mathrm{Ci}^{*}$.

Regarding the prevalence of double mutation in BCP in isolates of genotype $\mathrm{HBV} / \mathrm{F}$, there are different results. In fact, in Brazilian patients with chronic infection, the BCP double mutation was described in $90 \%$ of $\mathrm{HBV} / \mathrm{F}$ isolates; this double mutation was not identified in any other samples of these studies $[68,69]$.

Several authors have proposed that HBV genotype and BCP mutants could be related with liver disease severity. Although HBV/B and HBV/C circulate in Asia, patients with diagnosis of HBV-related HCC present a higher prevalence of HBV/C infection $[9,12,13]$. Similar findings have been reported for HBV/F, in a prospective study of 258 patients with chronic HBV infection; after a mean followup of 94 months, the mortality rate related to liver disease was more frequent in cases of genotype HBV/F than $\mathrm{HBV} / \mathrm{A}$ and HBV/D infection [14]. Livingston et al. also described an association of HBV/F and liver disease severity, in particular HCC risk. They compared the frequency of HBV/F in Alaska natives with chronic hepatitis $B$ infection with or without HCC; the frequency of genotype HBV/F was $68 \%$ and $18 \%$, respectively [15]. This finding suggested a higher risk of HCC development in HBV/F cases [15, 60]. SanchezTapias et al. and Livingston et al. described that genotype HBV/F, autochthonous to America, could be related with poor clinical outcome and higher HCC risk development; however, a higher number of studies should be developed for a stronger support of these findings.

In addition, the present study is the first report of A1762T/G1764A in Colombian HBV isolates. Recent studies assign a more important role to A1762T/G1764A in hepatocarcinogenesis than the HBV genotype itself. It has been 
demonstrated that the BCP double mutation generates a new binding site for the transcription factor HNF1, regulating pgRNA transcription and promoting an enhancement of HBV replicative activity [70]. In patients with HCC due to $\mathrm{HBV}$ infection, isolates belonging to genotype $\mathrm{HBV} / \mathrm{C}$ carry a higher frequency of A1762T/G1764A compared to HBV/B strains $[4,9,71,72]$. In our study, the presence of BCP double mutation correlates with HCC diagnosis in those patients.

This study corresponds to the first description of endstage liver diseases and the molecular characterization of $\mathrm{HBV}$ and $\mathrm{HCV}$ in cirrhosis and $\mathrm{HCC} / \mathrm{Ci}^{*}$ cases in Colombia. Genotype HCV/1 and genotype HBV/F (subgenotype F3) were detected in samples belonging to Colombian patients. This result agrees with previous studies and in the case of $\mathrm{HBV}$ with genetic founder populations in Colombia. Additionally, HBV/F3 and HBV/F1a were characterized in isolates from patients from Venezuela and El Salvador, respectively. The HBV and HCV subgenotyping/subtyping results obtained in the present study are according to the geographic pattern and predominance described for these hepatotropic viruses, especially subgenotypes HBV/F1a and $\mathrm{HBV} / \mathrm{F} 3$ in Central and South America, respectively.

On the other hand, mutation of A1762T/G1764A was characterized in isolates from patients with HCC. Although the double mutant has been related with higher risk of HCC development, the descriptive design of our study and limited sample size do not allow us to assess any type of statistical association between BCP mutant, genotype, and clinical outcome. Additionally studies will be necessary to determine whether $\mathrm{HCV} / 1 \mathrm{~b}, \mathrm{HBV} / \mathrm{F}$, and pre-C/C variants are associated with a higher risk of cirrhosis and HCC development.

Moreover, the statement of viral etiology and alcohol intake abuse in end-stage liver disease cases in Colombia and Latin America should be explored in further case-control studies.

\section{Acknowledgments}

The authors would like to thank Dr. Francisco Javier Diaz for his contribution to the phylogenetic analysis and Dr. AnneLise Haenni for manuscript review. This study was supported by the Departamento Nacional de Ciencia Innovación y Tecnologia (Grant: 115041 6445) and University of Antioquia (Codi Grant: E01157-CIM 2431).

\section{References}

[1] J. F. Perz, G. L. Armstrong, L. A. Farrington, Y. J. F. Hutin, and B. P. Bell, "The contributions of hepatitis B virus and hepatitis $\mathrm{C}$ virus infections to cirrhosis and primary liver cancer worldwide," Journal of Hepatology, vol. 45, no. 4, pp. 529-538, 2006.

[2] D. Lavanchy, "Hepatitis B virus epidemiology, disease burden, treatment, arid current and emerging prevention and control measures," Journal of Viral Hepatitis, vol. 11, no. 2, pp. 97-107, 2004.

[3] Globocan, "2002 World Health Organization,” http://wwwdep.iarc.fr/.
[4] C. J. Liu, B. F. Chen, P. J. Chen et al., "Role of hepatitis B viral load and basal core promoter mutation in hepatocellular carcinoma in hepatitis B carriers," Journal of Infectious Diseases, vol. 193, no. 9, pp. 1258-1265, 2006.

[5] C. J. Liu and J. H. Kao, "Hepatitis B virus-related hepatocellular carcinoma: epidemiology and pathogenic role of viral factors," Journal of the Chinese Medical Association, vol. 70, no. 4, pp. 141-145, 2007.

[6] D. Y. K. But, C. L. Lai, and M. F. Yuen, "Natural history of hepatitis-related hepatocellular carcinoma," World Journal of Gastroenterology, vol. 14, no. 11, pp. 1652-1656, 2008.

[7] C. M. Lee, C. Hung, S. N. Lu, and C. S. Changchien, "Hepatitis $\mathrm{C}$ virus genotypes: clinical relevance and therapeutic implications," Chang Gung Medical Journal, vol. 31, no. 1, pp. 16-25, 2008.

[8] C. L. Lin and J. H. Kao, "Hepatitis B viral factors and clinical outcomes of chronic hepatitis B," Journal of Biomedical Science, vol. 15, no. 2, pp. 137-145, 2008.

[9] J. H. Kao, P. J. Chen, M. Y. Lai, and D. S. Chen, "Hepatitis B genotypes correlate with clinical outcomes in patients with chronic hepatitis B," Gastroenterology, vol. 118, no. 3, pp. 554$559,2000$.

[10] A. Tsubota, Y. Arase, F. Ren, H. Tanaka, K. Ikeda, and H. Kumada, "Genotype may correlate with liver carcinogenesis and tumor characteristics in cirrhotic patients infected with hepatitis B virus subtype adw," Journal of Medical Virology, vol. 65, no. 2, pp. 257-265, 2001.

[11] R. N. Chien, C. T. Yeh, S. L. Tsai, C. M. Chu, and Y. F. Liaw, "Determinants for sustained HBeAg response to lamivudine therapy," Hepatology, vol. 38, no. 5, pp. 1267-1273, 2003.

[12] H. L. Y. Chan, A. Y. Hui, M. L. Wong et al., "Genotype C hepatitis $\mathrm{B}$ virus infection is associated with an increased risk of hepatocellular carcinoma," Gut, vol. 53, no. 10, pp. 14941498, 2004.

[13] M. W. Yu, S. H. Yeh, P. J. Chen et al., "Hepatitis B virus genotype and DNA level and hepatocellular carcinoma: a prospective study in men," Journal of the National Cancer Institute, vol. 97, no. 4, pp. 265-272, 2005.

[14] J. M. Sánchez-Tapias, J. Costa, A. Mas, M. Bruguera, and J. Rodés, "Influence of hepatitis B virus genotype on the longterm outcome of chronic hepatitis B in western patients," Gastroenterology, vol. 123, no. 6, pp. 1848-1856, 2002.

[15] S. E. Livingston, J. P. Simonetti, B. J. McMahon et al., "Hepatitis B virus genotypes in Alaska Native people with hepatocellular carcinoma: preponderance of genotype F," Journal of Infectious Diseases, vol. 195, no. 1, pp. 5-11, 2007.

[16] J. H. Kao, N. H. Wu, P. J. Chen, M. Y. Lai, and D. S. Chen, "Hepatitis B genotypes and the response to interferon therapy," Journal of Hepatology, vol. 33, no. 6, pp. 998-1002, 2000.

[17] F. Tacke, C. Gehrke, T. Luedde, A. Heim, M. P. Manns, and C. Trautwein, "Basal core promoter and precore mutations in the hepatitis B virus genome enhance replication efficacy of lamivud-ine-resistant mutants," Journal of Virology, vol. 78, no. 16, pp. 8524-8535, 2004.

[18] M. J. Tong, L. M. Blatt, J. H. Kao, J. T. Cheng, and W. G. Corey, "Basal core promoter T1762/A1764 and precore A1896 gene mutations in hepatitis B surface antigen-positive hepatocellular carcinoma: a comparison with chronic carriers," Liver International, vol. 27, no. 10, pp. 1356-1363, 2007.

[19] Y. Wang, L. Wei, D. Jiang et al., "In vitro resistance to interferon-alpha of hepatitis B virus with basic core promoter double mutation," Antiviral Research, vol. 75, no. 2, pp. 139$145,2007$. 
[20] F. Cortés-Mancera and M. C. Navas, "Antiviral treatment response and clinical outcome of Hepatitis B virus infection: impact of genotype and precore/core variants," Infection, vol. 3, pp. 201-216, 2008.

[21] M. Devesa, C. L. Loureiro, Y. Rivas et al., "Subgenotype diversity of hepatitis B Virus American Genotype F in Amerindians from Venezuela and the general population of Colombia," Journal of Medical Virology, vol. 80, no. 1, pp. 20 26, 2008.

[22] M. V. Alvarado Mora, C. M. Romano, M. S. Gomes-Gouvêa et al., "Molecular characterization of the Hepatitis B virus genotypes in Colombia: a Bayesian inference on the genotype F," Infection, Genetics and Evolution, vol. 11, no. 1, pp. 103-108, 2011.

[23] G. B. Zeng, S. J. Wen, Z. H. Wang, L. Yan, J. Sun, and J. L. Hou, "A novel hepatitis B virus genotyping system by using restriction fragment length polymorphism patterns of S gene amplicons," World Journal of Gastroenterology, vol. 10, no. 21, pp. 3132-3136, 2004.

[24] S. W. Chan, F. McOmish, E. C. Holmes et al., "Analysis of a new hepatitis $C$ virus type and its phylogenetic relationship to existing variants," Journal of General Virology, vol. 73, no. 5, pp. 1131-1141, 1992.

[25] F. M. Cortés-Mancera, J. C. Restrepo, G. Osorio, S. Hoyos, G. Correa, and M. C. Navas, "Occult hepatitis C virus infection in a re-transplanted patient with liver failure of unknown etiology," Revista Colombiana de Gastroenterologia, vol. 25, no. 1, pp. 76-85, 2010.

[26] S. Gunther, B. C. Li, S. Miska, D. H. Kruger, H. Meisel, and H. Will, "A novel method for efficient amplification of whole hepatitis B virus genomes permits rapid functional analysis and reveals deletion mutants in immunosuppressed patients," Journal of Virology, vol. 69, no. 9, pp. 5437-5444, 1995.

[27] X. Hu, H. S. Margolis, R. H. Purcell, J. Ebert, and B. H. Robertson, "Identification of hepatitis $\mathrm{B}$ virus indigenous to chimpanzees," Proceedings of the National Academy of Sciences of the United States of America, vol. 97, no. 4, pp. 1661-1664, 2000.

[28] S. Schaefer, D. Glebe, U. C. Wend, J. Oyunbileg, and W. H. Gerlich, "Universal primers for real-time amplification of DNA from all known Orthohepadnavirus species," Journal of Clinical Virology, vol. 27, no. 1, pp. 30-37, 2003.

[29] H. Norder, A. M. Couroucé, and L. O. Magnius, "Complete nucleotide sequences of six hepatitis B viral genomes encoding the surface antigen subtypes ayw4, adw4q-, and adrq- and their phylogenetic classification," Archives of Virology, vol. 8, pp. 189-199, 1993.

[30] J. M. Llovet and M. Beaugrand, "Hepatocellular carcinoma: present status and future prospects," Journal of Hepatology, vol. 38, no. 1, pp. S136-S149, 2003.

[31] D. Schuppan and N. H. Afdhal, "Liver cirrhosis," The Lancet, vol. 371, no. 9615, pp. 838-851, 2008.

[32] F. de la Hoz, L. Perez, M. de Neira, and A. J. Hall, "Eight years of hepatitis B vaccination in Colombia with a recombinant vaccine: factors influencing hepatitis $B$ virus infection and effectiveness," International Journal of Infectious Diseases, vol. 12, no. 2, pp. 183-189, 2008.

[33] World Health Organization, "Hepatitis C-Global prevalence (update)," Weekly Epidemiological Record, vol. 75, pp. 18-19, 2000.

[34] M. Beltrán, M. Ayala, and R. Ching, "Situación actual del tamizaje en bancos de sangre," Biomédica, vol. 16, no. 2, pp. 51-56, 1997.
[35] M. Beltrán, J. Raad, M. Ayala, and R. Ching, "Tamizaje de enfermedades infecciosas en bancos de sangre. Colombia, 1995," Biomédica, vol. 17, no. 2, pp. 137-142, 1997.

[36] B. A. Cortés, M. Beltrán, B. Olaya, and M. Hernández, "Riesgo de enfermedades infecciosas transmitidas por transfusión en el Valle del Cauca, Colombia," Colombia Medica, vol. 30, no. 1, pp. 13-18, 1999.

[37] G. Muñoz, M. Velasco, V. Thiers et al., "Prevalence and genotypes of hepatitis $\mathrm{C}$ virus in blood donors and in patients with chronic liver disease and hepatocarcinoma in a Chilean population," Revista médica de Chile, vol. 126, no. 9, pp. 10351042, 1998.

[38] A. Soza R and M. López-Lastra, "Hepatitis C in Chile: burden of the disease," Revista Medica de Chile, vol. 134, no. 6, pp. 777-788, 2006.

[39] E. Fassio, S. Díaz, C. Santa et al., "Etiology of hepatocellular carcinoma in Latin America: a prospective, multicenter, international study," Annals of Hepatology, vol. 9, no. 1, pp. 63-69, 2010.

[40] N. Méndez-Sánchez, J. R. Aguilar-Ramírez, A. Reyes et al., "Etiology of liver cirrhosis in Mexico," Ann Hepatol, vol. 3, no. 1, pp. 30-33, 2004.

[41] J. Cristina, "Genetic diversity and evolution of hepatitis C virus in the Latin American region," Journal of Clinical Virology, vol. 34, no. 2, pp. S1-S7, 2005.

[42] R. C. Botero, E. Rojas, V. Idrovo, E. Ponce, and F. Sierra, "Genotipos del virus de la Hepatitis C (HCV) en Santa Fé de Bogotá," Revista Colombiana de Gastroenterología, vol. 12, pp. 15-20, 1997.

[43] C. Santamaría, E. de Lima, and J. Holguín, "Hallazgos histológicos en infección crónica por el virus de la hepatitis C y su correlación con el genotipo viral, en Cali," Colombia Medica, vol. 29, no. 1, pp. 20-23, 1998.

[44] A. Yepes, C. Alvarez, J. C. Restrepo, G. Correa, J. C. Zapata, and A. E. Arango, "Viral genotypes in patients with hepatitis C virus infection in Medellín," Gastroenterologia y Hepatologia, vol. 25, no. 5, pp. 334-335, 2002.

[45] M. V. Mora, C. M. Romano, M. S. Gomes-Gouvêa, M. F. Gutiérrez, F. J. Carrilho, and J. R. Pinho, "Molecular characterization, distribution, and dynamics of hepatitis $\mathrm{C}$ virus genotypes in blood donors in Colombia," Journal of Medical Virology, vol. 82, no. 11, pp. 1889-1898, 2010.

[46] S. A. Raza, G. M. Clifford, and S. Franceschi, "Worldwide variation in the relative importance of hepatitis $\mathrm{B}$ and hepatitis C viruses in hepatocellular carcinoma: a systematic review," British Journal of Cancer, vol. 96, no. 7, pp. 1127-1134, 2007.

[47] S. Bruno, A. Crosignani, P. Maisonneuve, S. Rossi, E. Silini, and M. U. Mondelli, "Hepatitis C virus genotype $1 \mathrm{~b}$ as a major risk factor associated with hepatocellular carcinoma in patients with cirrhosis: a seventeen-year prospective cohort study," Hepatology, vol. 46, no. 5, pp. 1350-1356, 2007.

[48] S. Raimondi, S. Bruno, M. U. Mondelli, and P. Maisonneuve, "Hepatitis $\mathrm{C}$ virus genotype $\mathrm{lb}$ as a risk factor for hepatocellular carcinoma development: a meta-analysis," Journal of Hepatology, vol. 50, no. 6, pp. 1142-1154, 2009.

[49] Sivigila, "Sistema de Vigilancia en Salud Pública," Informe Quincenal Epidemiológico Nacional, vol. 11, pp. 49-64, 2006.

[50] Sivigila, "Sistema de Vigilancia en Salud Pública," Informe Quincenal Epidemiológico Nacional, vol. 11, pp. 279-312, 2006.

[51] N. M. Forones, L. A. Queiroz, V. F. Blum et al., "Hepatocarcinoma: analysis of 14 cases," Revista da Associacao Medica Brasileira, vol. 40, no. 4, pp. 300-302, 1994.

[52] C. S. Gonçalves, F. E. L. Pereira, and L. C. C. Gayotto, "Hepatocellular carcinoma in Brazil: report of a national 
survey (Florianópolis, SC, 1995)," Revista do Instituto de Medicina Tropical de Sao Paulo, vol. 39, no. 3, pp. 165-170, 1997.

[53] E. C. Branco Mello Miranda, L. D. J. Pereira Mioa, I. D. S. Abraçado Amaral et al., "Hepatitis B and C virus infection and the hepatocellular carcinoma in the East Amazon, Brazil," Revista da Sociedade Brasileira de Medicina Tropical, vol. 37, no. 2, pp. 47-51, 2004.

[54] G. C. Leão-Filho, E. P. A. Lopes, A. A. Ferrazaz et al., "Hepatitis $G$ virus infection in patients with hepatocellular carcinoma in Recife, Brazil," Japanese Journal of Clinical Oncology, vol. 37, no. 8, pp. 632-636, 2007.

[55] E. Ruiz, M. Almonte, R. Pizarro, J. Celis, J. A. Montalbelti, and R. Urbano, "Hepatitis B and C virus infection as risk factors for Hepatocarcinoma in Peru: case and control study," Revista de Gastroenterología del Perú, vol. 18, pp. 199-212, 1998.

[56] E. Ruiz, J. Sanchez, J. Celis et al., "Short and long-term results of liver resection for hepatocarcinoma in Peru: a Peruvian single center experience on 232 cases," Revista de Gastroenterología del Perú, vol. 27, no. 3, pp. 223-237, 2007.

[57] C. Manterola, S. Muñoz, J. C. Araya, C. Calderón, and M. S. Barroso, "Carcinoma hepatocellular. Description of verified clinical characteristics in a region of Southern Chile," Revista médica de Chile, vol. 128, pp. 887-895, 2000.

[58] L. J. López-García, D. H. Toro, H. Mayol, J. Martínez-Souss, M. I. Dueño, and F. Rodríguez-Pérez, "Hepatocellular carcinoma: ten years experience among veterans in Puerto Rico," Puerto Rico Health Sciences Journal, vol. 26, no. 2, pp. 103-107, 2007.

[59] A. R. Jaysoom, P. O. Vicente, G. V. Cristina, C. Andra, C. M. Luis, and S. F. Roque, "Etiology, survival, complications and mortality in liver cirrhosis in Ecuador, 15 years retrospective evaluation (1989-2003)," Gastroenterol Latinoam, vol. 17, no. 1, pp. 29-34, 2006.

[60] M. Devesa and F. H. Pujol, "Hepatitis B virus genetic diversity in Latin America," Virus Research, vol. 127, no. 2, pp. 177-184, 2007.

[61] L. G. Carvajal-Carmona, I. D. Soto, N. Pineda et al., "Strong Amerind/white sex bias and a possible Sephardic contribution among the founders of a population in Northwest Colombia," American Journal of Human Genetics, vol. 67, no. 5, pp. 1287$1295,2000$.

[62] G. Bedoya, P. Montoya, J. García et al., "Admixture dynamics in Hispanics: a shift in the nuclear genetic ancestry of a South American population isolate," Proceedings of the National Academy of Sciences of the United States of America, vol. 103, no. 19, pp. 7234-7239, 2006.

[63] M. V. Alvarado Mora, C. M. Romano, M. S. Gomes-Gouvêa, M. F. Gutierrez, F. J. Carrilho, and J. R.R. Pinho, "Molecular epidemiology and genetic diversity of hepatitis B virus genotype E in an isolated Afro-Colombian community," Journal of General Virology, vol. 91, no. 2, pp. 501-508, 2010.

[64] F. Cuellar-Ambrosi, M. C. Mondragon, M. Figueroa, C. Prehu, F. Galacteros, and A. Ruiz-Linares, "Sickle cell anemia and $\beta$ globin gene cluster haplotypes in Colombia," Hemoglobin, vol. 24, no. 3, pp. 221-225, 2000.

[65] T. T. T. Huy, H. Ushijima, T. Sata, and K. Abe, "Genomic characterization of HBV genotype $\mathrm{F}$ in Bolivia: genotype F subgenotypes correlate with geographic distribution and T1858 variant," Archives of Virology, vol. 151, no. 3, pp. 589597, 2006.

[66] C. M. Chu, C. T. Yeh, C. S. Lee, I. S. Sheen, and Y. F. Liaw, "Precore stop mutant in HBeAg-positive patients with chronic hepatitis $\mathrm{B}$ : clinical characteristics and correlation with the course of HBeAg-to-anti-HBe seroconversion," Journal of Clinical Microbiology, vol. 40, no. 1, pp. 16-21, 2002.

[67] A. S. F. Lok, U. Akarca, and S. Greene, "Mutations in the precore region of hepatitis B virus serve to enhance the stability of the secondary structure of the pre-genome encapsidation signal," Proceedings of the National Academy of Sciences of the United States of America, vol. 91, no. 9, pp. 4077-4081, 1994.

[68] L. de Castro, C. Niel, and S. A. Gomes, "Low frequency of mutations in the core promoter and precore regions of hepatitis B virus in anti-HBe positive Brazilian carriers," BMC Microbiology, vol. 1, p. 10, 2001.

[69] R. Sitnik, J. R. R. Pinho, D. A. Bertolini, A. P. Bernardini, L. C. da Silva, and F. J. Carrilho, "Hepatitis B virus genotypes and precore and core mutants in Brazilian patients," Journal of Clinical Microbiology, vol. 42, no. 6, pp. 2455-2460, 2004.

[70] J. Li, V. E. Buckwold, M. W. Hon, and J. H. Ou, "Mechanism of suppression of hepatitis B virus precore RNA transcription by a frequent double mutation," Journal of Virology, vol. 73, no. 2, pp. 1239-1244, 1999.

[71] J. H. Kao, P. J. Chen, M. Y. Lai, and D. S. Chen, "Basal core promoter mutations of hepatitis $\mathrm{B}$ virus increase the risk of hepatocellular carcinoma in hepatitis B carriers," Gastroenterology, vol. 124, no. 2, pp. 327-334, 2003.

[72] A. Kramvis, K. Arakawa, M. C. Yu, R. Nogueira, D. O. Stram, and M. C. Kew, "Relationship of serological subtype, basic core promoter and precore mutations to genotypes/subgenotypes of hepatitis B virus," Journal of Medical Virology, vol. 80, no. 1, pp. 27-46, 2008. 


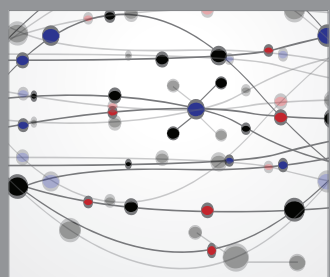

The Scientific World Journal
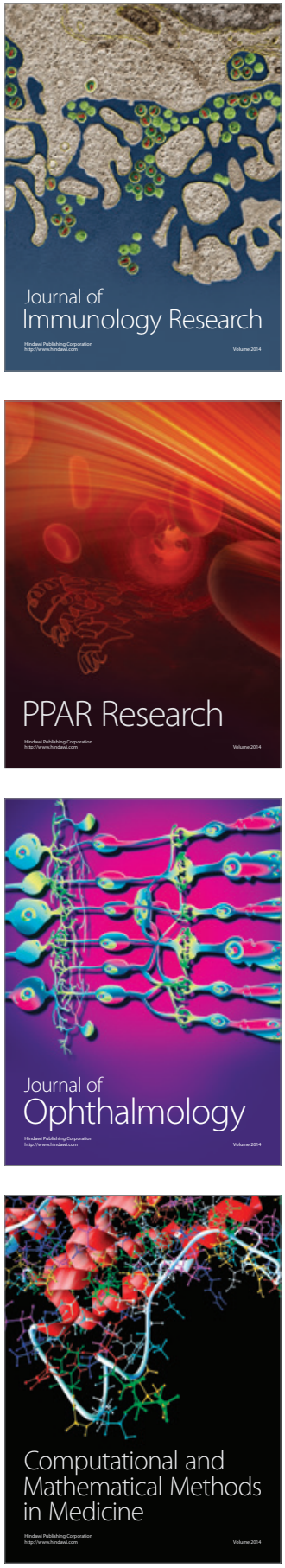

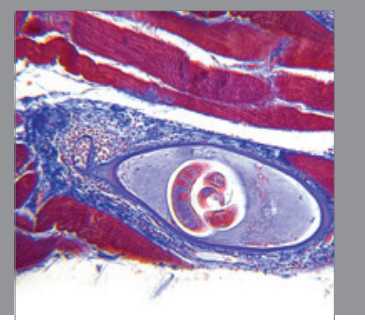

Gastroenterology

Research and Practice
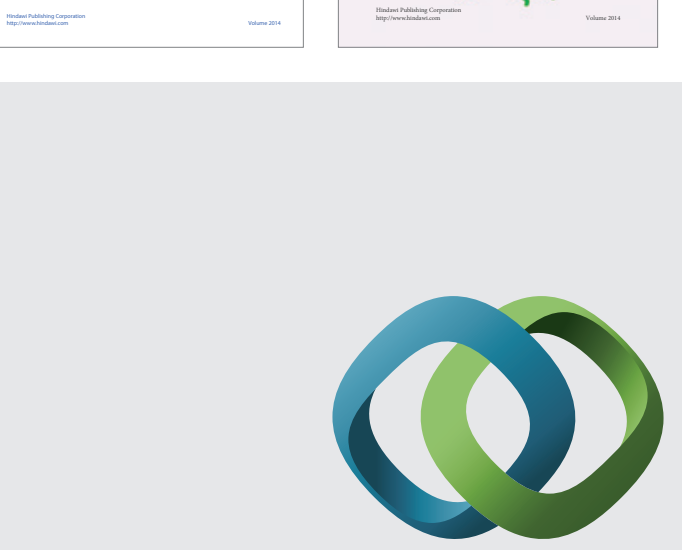

\section{Hindawi}

Submit your manuscripts at

http://www.hindawi.com
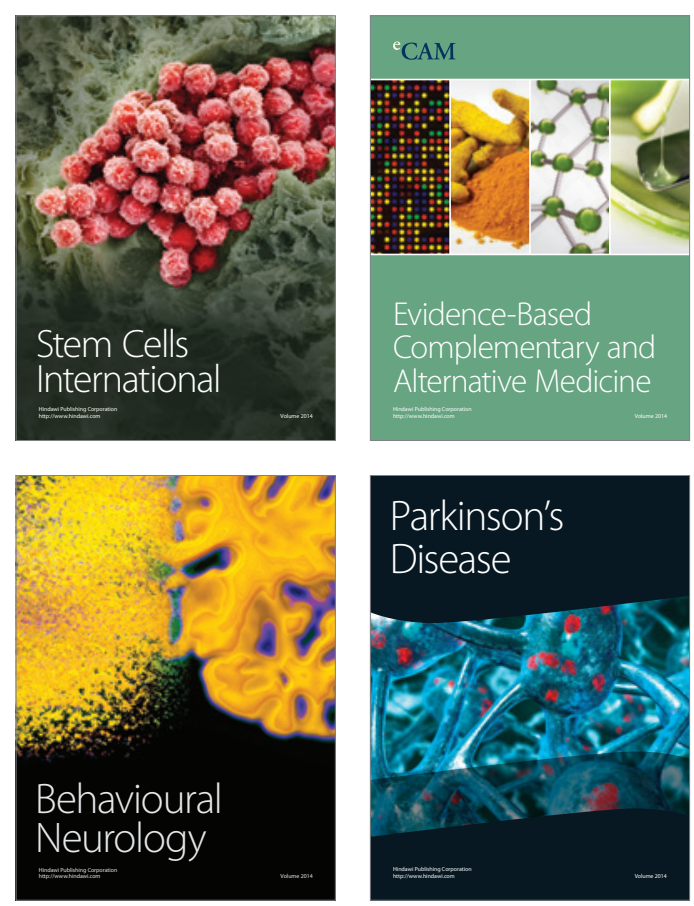

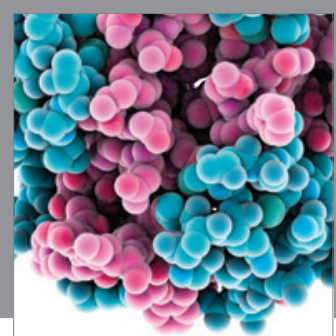

Journal of
Diabetes Research

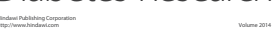

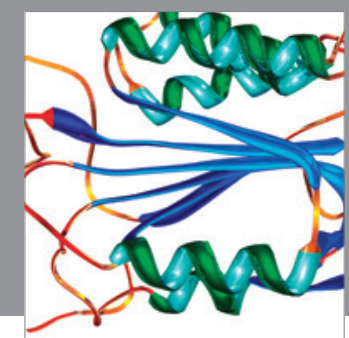

Disease Markers
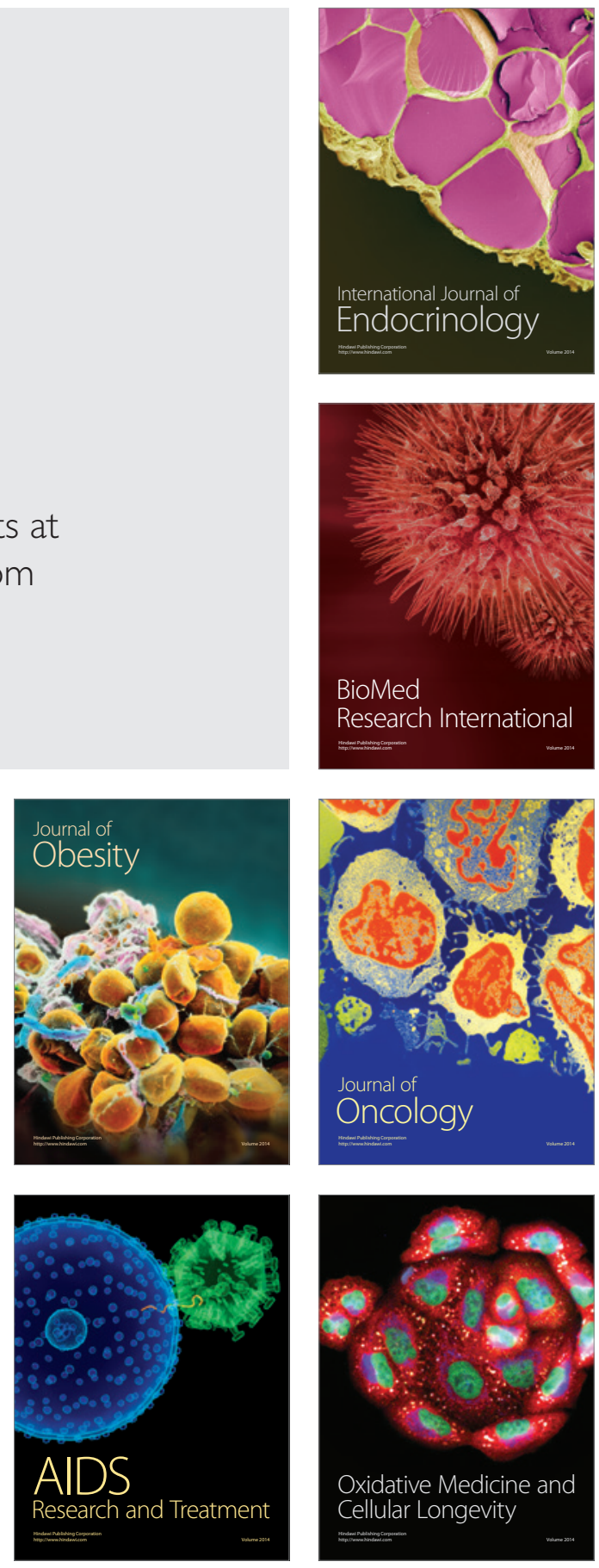